\title{
Heritability and Expression of Selected Mixograph Parameters in Progeny of Parents Varying for Mixing Time
}

\author{
F. S. Pelser, M.T. Labuschagne*, B. Wentzel and A. van Biljon \\ University of the Free State Faculty of Health Sciences Bloemfontein, Free State South Africa
}

(Received 10 November 2015; Accepted 19 January 2016;

Communicated by F. Békés)

\begin{abstract}
The mixograph performs certain rheological measurements during dough mixing and is a good predictor of wheat end-use quality. The aim of this study was to determine the expression and the heritability of mixing characteristics measured with Mixsmart ${ }^{\circledR}$ software and some quality characteristics in hard red spring wheat parents and their $\mathrm{F}_{1}$ progeny. Six parents varying in midline peak time and envelope peak time were crossed in a half diallel design. Parents and progeny were planted in three different environments. General combining ability (GCA) was a significant source of variation for the measured characteristics, and parents differed widely in terms of GCA effects. Midline-development time, -peak integral and -peak time showed high narrow sense heritability. Envelope peak-integral and -tail width displayed high narrow sense heritability for some, but not all locations. High GCA:SCA (specific combining ability) ratios indicated the prevalence of additive gene effects for midline-development time, -peak integral and -peak time, indicating that these characteristics are largely genetically determined, and that selection for them should lead to genetic gain.
\end{abstract}

Keywords: diallel, inheritance, Mixsmart, wheat quality

\section{Introduction}

Wheat breeding produces a large amount of cross combinations from potential parents, therefore a multistage selection process is used. The first stage entails the selection of parental lines by evaluation of their performance; in the second stage parental lines are selected based on their GCA (Longin et al. 2009). GCA and large GCA:SCA ratios indicate the presence of additive gene effects, which could be used in breeding due to additive gene effects being retained in progeny, while SCA and small GCA:SCA ratios are an indication of dominance and epistasis (Ahmed et al. 1991). Narrow sense heritability is an indication of phenotypic variance due to additive genetic variability. Parameters with high heritability are beneficial in the selection of new cultivars (Barnard et al. 2002; Neacşu et al. 2009).

The mixograph performs certain rheological measurements during dough mixing and is a good predictor of end-use quality (Bordes et al. 2008). Rate of dough development is

\footnotetext{
*Corresponding author; E-mail: labuscm@ufs.ac.za
} 
the most used measurement of a mixograph (Barnard et al. 2002). Peak time is an indication of time that is needed for dough to reach maximum consistency or first indication of dough weakening. Strong doughs tend to have long mixing times, high peak values and band widths and low resistance to breakdown (Mao et al. 2013). Quality and quantity of protein in wheat can increase absorption, thus influencing peak time and mixograph peak value. Different genotypes can all have $12 \%$ flour protein content, but differ for mixing properties. This is due to the quality of protein (Finney et al. 1987). Variations in dough rheological properties have been found to be influenced by genotype but also by environment (Li et al. 2013). Bergman et al. (1998) found peak time and flour protein content to have high heritability, but this was contradicted by the findings of Barnard et al. (2002) and Morojele and Labuschagne (2013) who found mixing development time to be a parameter with low narrow sense heritability. The aim of this study was to determine the expression and heritability of mixograph parameters and some quality characteristics in $\mathrm{F}_{1}$ progeny of parents with varying midline and envelope peak time values in three different locations.

\section{Materials and Methods}

\section{Plant material}

Six South African spring wheat genotypes with varying midline and envelope peak time values (Table 1) were obtained from PANNAR ${ }^{\circledR}$. The mixing time data came from the previous two production seasons, but only the averages are shown. As the information on parents is confidential, all parents and progeny were coded. The parents were crossed in the glasshouse in a half diallel mating design, excluding reciprocals, to produce $15 \mathrm{~F}_{1}$ crosses.

Table 1. Localities and fertiliser used for $\mathrm{F}_{1}$ trials and parental material used with their mixing characteristics

\begin{tabular}{|c|c|c|c|c|c|}
\hline Location & Province & Latitude & Longitude & Elevation (m) & Fertiliser \\
\hline Petrusburg & Free State & $29^{\circ} 7^{\prime} 18.912^{\prime \prime S}$ & $25^{\circ} 24^{\prime} 49.388^{\prime \prime} \mathrm{E}$ & 1247 & $180 \mathrm{~N}: 40 \mathrm{P}: 20 \mathrm{~K}$ \\
\hline Orania & Northern Cape & $29^{\circ} 49^{\prime} 25.82^{\prime \prime} \mathrm{S}$ & $24^{\circ} 24^{\prime} 48.056^{\prime \prime} \mathrm{E}$ & 1126 & $260 \mathrm{~N}: 173 \mathrm{P}: 86 \mathrm{~K}$ \\
\hline Magogong & North West & $27^{\circ} 39^{\prime} 25.28^{\prime \prime} \mathrm{S}$ & $24^{\circ} 48^{\prime} 44.052^{\prime \prime} \mathrm{E}$ & 1175 & $180 \mathrm{~N}: 40 \mathrm{P}: 20 \mathrm{~K}$ \\
\hline Genotype & $\begin{array}{l}\text { Midline peak time } \\
\text { (min) }\end{array}$ & $\begin{array}{l}\text { Envelope peak time } \\
\text { (min) }\end{array}$ & & & \\
\hline Parent 1 & 2.23 & 1.93 & & & \\
\hline Parent 2 & 2.26 & 2.06 & & & \\
\hline Parent 3 & 2.39 & 2.10 & & & \\
\hline Parent 4 & 2.48 & 2.26 & & & \\
\hline Parent 5 & 2.27 & 1.82 & & & \\
\hline Parent 6 & 2.82 & 2.12 & & & \\
\hline
\end{tabular}

$\mathrm{S}=$ South, $\mathrm{E}=$ East, $\mathrm{N}=$ Nitrogen, $\mathrm{P}=$ Phosphorus, $\mathrm{K}=$ Potassium 


\section{Field trials}

Field trials were conducted in irrigated locations in three different provinces in South Africa (Table 1). The $\mathrm{F}_{1}$ hybrids together with the parents were planted in June/July 2012 and harvested in November/December 2012. Experimental plots were planted one row per cultivar (1 $\mathrm{m}$ long, with a $30 \mathrm{~cm}$ inter row spacing) using a randomized complete block design with three replications. The plot size was small due to limited seed. Fertiliser mixtures, nitrogen $(\mathrm{N})$ : phosphorus $(\mathrm{P})$ : potassium $(\mathrm{K})$, were applied (Table 1), which is optimal for each production area. Irrigation was applied to create optimal production conditions.

\section{Laboratory methods}

Laboratory analysis was done at the Small Grain Institute (Bethlehem). All the grain samples were evaluated for grain characteristics, after which they were conditioned and milled. Tests were done according to the American Association of Cereal Chemists (AACC) standards (AACC, 2000) and included conditioning (AACC procedure 26-95), mixograph analyses (AACC method 54-40A), flour protein content (AACC Method 3911.01), Sodium Dodecyl Sulphate (SDS) sedimentation volume (AACC 56-70) and falling number (AACC method 56-81B). Using Mixsmart ${ }^{\circledR}$ software, 44 parameters can be measured on a single mixogram curve (Pon et al. 1989). These parameters result from measurements made at different heights, widths and slopes as well as areas on the mixogram curve (Walker and Walker 1992). In this study the 17 most repeatable Mixsmart parameters with acceptable coefficients of variation were included.

\section{Diallel analysis}

Analysis of GCA and SCA for the characteristics were done using Agrobase $2^{\text {nd }}$ Generation Software (Agronomix 2014). The relative magnitude of mean squares of GCA and SCA were determined using the GCA:SCA ratios. Heritability of characteristics was estimated as

$$
\mathrm{h}_{\mathrm{n}}^{2}=2 \sigma^{2} \mathrm{GCA} /\left(2 \sigma^{2} \mathrm{GCA}+\sigma^{2} \mathrm{SCA}+\sigma^{2} \mathrm{E}\right) .
$$

LSD for GCA and SCA was estimated as $\sqrt{\sigma^{2}(g i-g j)} \times t p$ (use of two sided table at $\mathrm{p}=0.05)$ and $\sqrt{\sigma^{2}(s i j)} \times t p(t$ table), respectively, where $g i$ and $g j$ are GCA effects of parents and sij is SCA effects of crosses (Dabholkar 1999).

\section{Results}

\section{Combining ability effects of parents}

Only GCA was discussed as SCA was not relevant in the context of this study, except for determining GCS:SCA ratios. Parent 1 was the best combiner for envelope peak time, midline peak value, SDS sedimentation volume, envelope left value and flour protein 
Table 2. Orania general combining ability effects of parents for mixograph parameters and selected quality characteristics

\begin{tabular}{|c|c|c|c|c|c|c|c|}
\hline \multirow{2}{*}{ Character } & \multirow{2}{*}{$\begin{array}{l}\text { LSD } \\
\text { GCA } \\
(0.05)\end{array}$} & \multicolumn{6}{|c|}{$\begin{array}{c}\text { GCA effect } \\
\text { Parent }\end{array}$} \\
\hline & & 1 & 2 & 3 & 4 & 5 & 6 \\
\hline ELV & 8.61 & 3.67 & 0.21 & 2.96 & -2.75 & -1.50 & -2.60 \\
\hline ELW & 6.43 & -0.29 & -0.64 & 4.10 & -2.34 & -0.11 & -0.72 \\
\hline MDT & 0.17 & -0.07 & -0.07 & 0.04 & -0.03 & -0.07 & 0.21 \\
\hline MPI & 10.51 & -0.16 & -3.06 & -4.53 & -0.44 & -3.28 & 11.48 \\
\hline MPT & 0.24 & -0.02 & -0.08 & -0.13 & -0.01 & -0.1 & 0.33 \\
\hline MPV & 1.35 & 0.68 & 0.17 & -0.45 & 0.07 & 0.35 & -0.83 \\
\hline MTI & 6.53 & 0.60 & -2.14 & -0.31 & -0.39 & 2.05 & -0.80 \\
\hline MTV & 0.97 & 0.01 & -0.45 & -0.50 & 0.21 & 0.10 & 0.63 \\
\hline EPI & 11.79 & -2.07 & -3.07 & 1.98 & -0.06 & -0.13 & 3.35 \\
\hline EPT & 0.52 & 0.09 & -0.12 & -0.12 & 0.08 & -0.01 & 0.08 \\
\hline EPV & 3.43 & -1.11 & 1.01 & 1.62 & -1.04 & 0.54 & -1.02 \\
\hline EPW & 9.13 & -4.29 & 1.82 & 4.11 & -2.16 & 0.02 & 0.54 \\
\hline ERI & 16.16 & -2.85 & -3.21 & 3.19 & -2.21 & 1.57 & 3.51 \\
\hline ERT & 0.85 & 0.19 & -0.18 & -0.17 & 0.06 & 0.03 & 0.07 \\
\hline ERV & 4.35 & -1.22 & 0.33 & 1.09 & -0.33 & 0.00 & 0.13 \\
\hline ETV & 1.30 & -0.22 & -0.95 & -0.17 & 0.16 & 0.13 & 1.04 \\
\hline ETW & 1.60 & -0.41 & -0.84 & 0.65 & -0.11 & -0.05 & 0.73 \\
\hline FLN & 85.89 & -18.65 & -12.11 & 8.64 & -24.49 & 45.26 & 1.35 \\
\hline FPC & 0.40 & 0.38 & -0.16 & -0.05 & -0.10 & -0.01 & 0.06 \\
\hline SDSVOL & 4.73 & 8.04 & -0.88 & -2.38 & -3.42 & -1.08 & -0.29 \\
\hline
\end{tabular}

$\mathrm{GCA}=$ General combining ability, $\mathrm{LSD}=$ Least significant difference, $\mathrm{ELV}=$ Envelope left value, $\mathrm{ELW}=$ Envelope left width, MDT $=$ Midline development time, MPI $=$ Midline peak integral, MPT $=$ Midline peak time, MPV $=$ Midline peak value, $\mathrm{MTI}=$ Midline tail integral, $\mathrm{MTV}=$ Midline tail value, $\mathrm{EPI}=$ Envelope peak integral, $\mathrm{EPT}=$ Envelope peak time, EPV $=$ Envelope peak value, $\mathrm{EPW}=$ Envelope peak width, $\mathrm{ERI}=$ Envelope right integral, $\mathrm{ERT}=$ Envelope right time, $\mathrm{ERV}=$ Envelope right value, ETV = Envelope tail value, ETW = Envelope tail width, FLN $=$ Falling number, FPC $=$ Flour protein content, SDSVOL $=$ Sodium Dodecyl Sulphate sedimentation volume, highest GCA effects indicated in bold.

content in Orania (Table 2). It was also the best combiner for flour protein content in Petrusburg as well as for envelope left value and envelope right time in Magogong (Tables 3 and 4). Parent 2 was the best combiner only for envelope left value in Petrusburg (Table 3). Parent 3 was the best combiner for falling number in Petrusburg and Magogong as well as for flour protein content in Magogong. Parent 3 was also the best combiner for envelope-left width, -peak value, -peak width and -tail value at Orania (Tables 2-4). Parent 4 was the best combiner in Magogong for envelope-left width, -midline tail value, -envelope peak time, -peak value and -tail integral as well as for envelopepeak width and -right value in Petrusburg. It was also the best combiner for envelope tail 
Table 3. Petrusburg general combining ability effects of parents for mixograph parameters and selected quality characteristics

\begin{tabular}{|c|c|c|c|c|c|c|c|}
\hline \multirow{2}{*}{ Character } & \multirow{2}{*}{$\begin{array}{l}\text { LSD } \\
\text { GCA } \\
(0.05) \\
\end{array}$} & \multicolumn{6}{|c|}{$\begin{array}{c}\text { GCA effect } \\
\text { Parent }\end{array}$} \\
\hline & & 1 & 2 & 3 & 4 & 5 & 6 \\
\hline ELV & 9.64 & 2.36 & 5.39 & -1.99 & -3.51 & 0.41 & -2.66 \\
\hline ELW & 3.81 & 0.59 & 1.71 & -0.39 & -1.36 & 0.63 & -1.18 \\
\hline MDT & 0.14 & -0.15 & -0.01 & 0.06 & -0.01 & -0.12 & 0.23 \\
\hline MPI & 6.85 & -4.51 & -1.97 & 3.74 & -1.27 & -2.98 & 7.00 \\
\hline MPT & 0.17 & -0.13 & -0.03 & 0.08 & -0.03 & -0.11 & 0.23 \\
\hline MPV & 1.61 & 0.30 & -0.53 & 0.20 & -0.21 & 1.00 & -0.77 \\
\hline MTI & 8.76 & -0.57 & -1.45 & 1.05 & 0.10 & 3.70 & -2.83 \\
\hline MTV & 3.61 & 0.30 & -0.14 & -0.43 & -0.13 & 0.96 & -0.55 \\
\hline EPI & 4.57 & -5.01 & -0.31 & 1.40 & 1.16 & -1.84 & 4.60 \\
\hline EPT & 0.16 & -0.17 & -0.04 & 0.07 & 0.00 & -0.11 & 0.25 \\
\hline EPV & 2.33 & -0.35 & -0.18 & 0.03 & 0.72 & 0.73 & -0.95 \\
\hline EPW & 3.60 & -0.75 & 0.79 & -0.34 & 1.58 & -0.62 & -0.67 \\
\hline ERI & 6.89 & -6.17 & 0.03 & 3.34 & 0.92 & -2.26 & 4.14 \\
\hline ERT & 0.33 & -0.16 & -0.05 & 0.22 & -0.11 & -0.15 & 0.25 \\
\hline ERV & 4.01 & -1.11 & 0.71 & -1.20 & 1.71 & 0.78 & -0.89 \\
\hline ETV & 4.71 & -0.09 & -0.07 & -0.60 & 0.06 & 1.60 & -0.90 \\
\hline ETW & 2.68 & -0.89 & 0.05 & -0.14 & 0.27 & 1.07 & -0.35 \\
\hline FLN & 37.26 & 3.42 & -9.54 & 15.58 & 9.16 & -4.67 & -13.96 \\
\hline FPC & 0.39 & 0.26 & -0.09 & -0.11 & -0.07 & 0.17 & -0.16 \\
\hline SDSVOL & 5.92 & 1.40 & -3.43 & 1.69 & -2.01 & -0.47 & 2.82 \\
\hline
\end{tabular}

$\mathrm{GCA}=$ General combining ability, $\mathrm{LSD}=$ Least significant difference, $\mathrm{ELV}=$ Envelope left value, $\mathrm{ELW}=$ Envelope left width, MDT $=$ Midline development time, MPI $=$ Midline peak integral, MPT $=$ Midline peak time, MPV $=$ Midline peak value, $\mathrm{MTI}=$ Midline tail integral, $\mathrm{MTV}=$ Midline tail value, $\mathrm{EPI}=$ Envelope peak integral, $\mathrm{EPT}=$ Envelope peak time, $\mathrm{EPV}$ $=$ Envelope peak value, $\mathrm{EPW}=$ Envelope peak width, $\mathrm{ERI}=$ Envelope right integral, $\mathrm{ERT}=$ Envelope right time, $\mathrm{ERV}=$ Envelope right value, ETV = Envelope tail value, ETW $=$ Envelope tail width, FLN $=$ Falling number, FPC $=$ Flour protein content, SDSVOL= Sodium Dodecyl Sulphate sedimentation volume, highest GCA effects indicated in bold.

value in Orania (Table 2). Parent 5 was the best combiner for midline tail integral and falling number in Orania as well as for envelope left width and midline-peak value, -tail integral and -tail value, and envelope-peak value, -tail value and -tail width in Petrusburg. It was also the best combiner for SDS sedimentation volume in Magogong (Table 4).

Parent 6 was the best overall combiner as it was the best combiner for midline-development time, -peak integral, -peak time, -tail value, and envelope-peak integral, -right integral and -tail width in Orania as well as for midline-development time, -peak integral, -peak time and envelope-peak integral, -peak time, -right integral and -right time and SDS sedimentation volume in Petrusburg. It was also the best combiner for midline-develop- 
ment time, -peak integral, -peak time and envelope-peak integral, -peak value, -peak width, -right integral, -right value, -tail value and -tail width in Magogong (Tables 2-4).

\section{GCA mean squares, GCA:SCA mean square ratios and heritability of mixograph parameters and quality characteristics}

The number of characteristics with significant GCA mean square values by far exceeded those with significant SCA mean squares (Table S1*). Orania had seven charac-

Table 4. Magogong general combining ability effects of parents for mixograph parameters and selected quality characteristics

\begin{tabular}{|c|c|c|c|c|c|c|c|}
\hline \multirow{2}{*}{ Character } & \multirow{2}{*}{$\begin{array}{c}\text { LSD } \\
\text { GCA } \\
(0.05)\end{array}$} & \multicolumn{6}{|c|}{$\begin{array}{c}\text { GCA effect } \\
\text { Parent }\end{array}$} \\
\hline & & 1 & 2 & 3 & 4 & 5 & 6 \\
\hline ELV & 10.56 & 1.81 & 0.39 & -1.67 & 1.02 & -2.31 & 0.77 \\
\hline ELW & 4.77 & 0.22 & -0.43 & 0.36 & 0.77 & -1.30 & 0.38 \\
\hline MDT & 0.19 & -0.06 & -0.09 & -0.13 & 0.07 & -0.05 & 0.25 \\
\hline MPI & 11.35 & -1.21 & -3.46 & -1.32 & 4.18 & -7.21 & 9.01 \\
\hline MPT & 0.19 & -0.06 & -0.10 & -0.08 & 0.07 & -0.05 & 0.21 \\
\hline MPV & 1.95 & -0.04 & -0.12 & 0.22 & 0.80 & -0.51 & -0.35 \\
\hline MTI & 23.64 & 1.82 & 0.63 & 2.45 & 6.12 & -15.44 & 4.43 \\
\hline MTV & 3.12 & -0.84 & 0.20 & -1.50 & 1.49 & -0.37 & 1.02 \\
\hline EPI & 9.04 & -2.31 & -1.27 & -1.73 & 3.39 & -3.03 & 4.96 \\
\hline EPT & 0.34 & -0.03 & 0.02 & -0.07 & 0.16 & -0.19 & 0.11 \\
\hline EPV & 2.96 & -0.72 & -0.44 & 0.06 & 0.42 & -1.06 & 1.74 \\
\hline EPW & 4.65 & -1.56 & -1.08 & -0.03 & -1.09 & -0.83 & 4.59 \\
\hline ERI & 11.43 & 0.31 & -2.07 & -1.7 & 2.63 & -5.19 & 6.02 \\
\hline ERT & 0.54 & 0.19 & 0.00 & -0.06 & 0.18 & -0.32 & 0.01 \\
\hline ERV & 4.38 & -1.08 & -0.80 & 0.75 & -0.09 & -1.06 & 2.28 \\
\hline ETV & 3.73 & -0.67 & 0.11 & -1.83 & 1.35 & -0.55 & 1.60 \\
\hline ETW & 1.17 & 0.41 & -3.57 & -0.43 & -0.34 & -0.40 & 1.12 \\
\hline FLN & 8.22 & 0.94 & -1.68 & 3.38 & -1.24 & 1.92 & -3.33 \\
\hline FPC & 0.41 & 0.09 & -0.11 & 0.12 & 0.08 & -0.01 & -0.17 \\
\hline SDSVOL & 5.59 & 2.43 & -3.61 & -0.86 & -1.36 & 3.14 & 0.26 \\
\hline
\end{tabular}

$\mathrm{GCA}=$ General combining ability, LSD = Least significant difference, ELV $=$ Envelope left value, ELW $=$ Envelope left width, MDT $=$ Midline development time, MPI $=$ Midline peak integral, MPT $=$ Midline peak time, MPV $=$ Midline peak value, $\mathrm{MTI}=$ Midline tail integral, $\mathrm{MTV}=$ Midline tail value, EPI $=$ Envelope peak integral, $\mathrm{EPT}=$ Envelope peak time, $\mathrm{EPV}$ $=$ Envelope peak value, $\mathrm{EPW}=$ Envelope peak width, $\mathrm{ERI}=$ Envelope right integral, $\mathrm{ERT}=$ Envelope right time, $\mathrm{ERV}=$ Envelope right value, $\mathrm{ETV}=$ Envelope tail value, $\mathrm{ETW}=$ Envelope tail width, $\mathrm{FLN}=$ Falling number, $\mathrm{FPC}=$ Flour protein content, SDSVOL= Sodium Dodecyl Sulphate sedimentation volume, highest GCA effects indicated in bold.

*Further details about the Electronic Supplementary Material (ESM) can be found at the end of the article. 
teristics with significant mean squares for GCA (flour protein content, midline- development time, -peak integral, -peak time, -tail value and envelope-tail value and -tail width) and one highly significant GCA mean square for SDS sedimentation volume. Petrusburg had four significant GCA mean squares (midline peak integral, and envelope-peak integral, -right integral and -right time) and three highly significant GCA mean squares (midline-development and -peak time and envelope peak time). Magogong showed six significant GCA mean squares (midline-development time and -peak time, -integral and envelope-peak width and -tail width and SDS sedimentation volume). High GCA:SCA mean square ratios were found for most of the characteristics for all three locations. Envelope peak time had high narrow sense heritability only in Petrusburg while midline development time and midline peak time showed high narrow sense heritability for all three locations.

\section{Discussion}

In order to improve the mixograph parameters and selected quality characteristics, parents with high GCA effects should be used as parental lines (Barnard et al. 2002). The South African quality standard SST 806 has a peak time ranging from $1.8 \mathrm{~min}$ to $3.8 \mathrm{~min}$ with an average of $2.4 \mathrm{~min}$. Thus a cultivar may not deviate from these values by more than $35 \%$ or less than $10 \%$ (SAGL, 2013). A predominance of GCA compared to SCA effects was reported by Gowda et al. (2012). As this was also seen in this study, the importance of additive genetic variances in the inheritance of characteristics in this set of material was emphasised. High GCA:SCA mean square ratios indicate high heritability and low influence of the environment (Barnard et al. 2002). Midline-development and -peak time and envelope peak time, SDS sedimentation volume and flour protein content (except for Magogong) had GCA:SCA mean square ratios above one, this is in accordance with the findings of Barnard et al. (2002) except for SDS sedimentation volume in their study which had a GCA:SCA mean square ratio below one. This is an indication of additive gene action and supports the high GCA values found for mixograph parameters and quality characteristics. This is important as peak time values are used for quality selection in breeding programmes (Neacşu et al. 2009). GCA:SCA mean square ratios below one are indicative of non-additive and dominant gene actions as was the case for envelope peak value for all the locations. These results are in accordance with Barnard et al. (2002) where GCA mean squares were significant for flour protein content, and both GCA and SCA were significant for mixograph development time. They found no significant GCA or SCA for SDS sedimentation volume contrary to what was found in this study.

Parameters with high heritability can be used by breeders and is beneficial in the selection of new cultivars (Neacşu et al. 2009). In the study of Gras and O'Brien (1992) it was found that mixing time had a medium to high heritability, this corresponded with the findings of this study. Miles et al. (2013) found genotype to be the largest contributor of variation for mixograph peak time, indicating a small environmental effect. This contradicts the findings of Barnard et al. (2002) and Morojele and Labuschagne (2013) where mixo- 
graph development time had low narrow sense heritability. They also found flour protein content and SDS sedimentation volume to have a low narrow sense heritability which contradicted the findings of Gras and O'Brien (1992) where flour protein content had a medium heritability. This could be due to different parents and locations used in this study compared to other studies, as flour protein content and SDS sedimentation volume are known to be influenced by environmental conditions (Labuschagne et al. 2009; Miles et al. 2014).

To conclude, this study showed that GCA was a significant source of variation for the characteristics studied. Midline-development time, -peak integral and -peak time showed very high narrow sense heritability. This is an indication that environment had little to no effect on these characteristics. In contrast to this, envelope-peak integral and tail-width displayed high narrow sense heritability for some, but not all locations. This indicates that environment influenced inheritance of these characteristics. High GCA:SCA ratios indicated the prevalence of additive gene effects for midline-development time, -peak integral and -peak time, indicating strong genetic effects for these characteristics, and that selection for them should lead to genetic gain. When making crosses, parents with good GCA can be used to obtain progeny with desired mixing characteristics. In order to improve the mixograph parameters and selected quality characteristics, parents with high GCA effects should be used as parental lines (Barnard et al. 2002).

\section{Acknowledgement}

This work was funded in part by the National Research Foundation of South Africa (UID 72056).

\section{References}

Agronomix Software, Inc. 2014. AGROBASE Generation II User's Manual. Version II, Revised Edition. www. agronomix.com. Agronomix Software. Winnipeg, MB, Canada.

Ahmed, Z., Singh, K.N., Srivastava, V.K. 1991. Grain quality characters in wheat. Indian J. of Genet. 51:84-89.

American Association of Cereal Chemists (AACC) 2000. Approved methods of the AACC, 10th edition. American Association of Cereal Chemists, Inc. St. Paul, Minnesota, USA.

Barnard, A.D., Labuschagne, M.T., van Niekerk, H.A. 2002. Heritability estimates of bread wheat quality traits in the Western Cape province of South Africa. Euphytica 127:115-122.

Bergman, C.J., Gualberto, D.G., Campbell, K.G., Sorrells, M.E., Finney, P.L. 1998. Genotype and environment effects on wheat quality traits in a population derived from a soft by hard cross. Cereal Chem. 75:729-737.

Bordes, J., Branlard, G., Oury, F.X., Charmet, G., Balfourier, F. 2008. Agronomic characteristics, grain quality and flour rheology of 372 bread wheats in a worldwide core collection. J. Cereal Sci. 48:569-579.

Dabholkar, A.R. 1999. Elements of Biometrical Genetics. Concept Publishing Company. New Delhi, India.

Finney, K.F., Yamazaki, W.T., Youngs, V.L., Rubenthaler, G.L. 1987. Quality of hard, soft and durum wheats. In: Heyne, E.G. (ed.), Wheat and Wheat Improvement, 2nd ed. Am. Soc. of Agron., Inc., Crop Sci. Soc. of Am., Inc, Soil Sci. Soc. of Am., Inc. USA. pp. 677-748.

Gowda, M., Longin, C.F.H., Lein, V., Reif, J.C. 2012. Relevance of specific versus general combining ability in winter wheat. Crop Sci. 52:2494-2500.

Gras, P.W., O’Brien, L. 1992. Application of a 2-gram mixograph to early generation selection for dough strength. Cereal Chem. 69:254-257. 
Labuschagne, M.T., Elago, O., Koen, E. 2009. The influence of temperature extremes on some quality and starch characteristics in bread, biscuit and durum wheat. J. Cereal Sci. 49:184-189.

Li, Y., Wu, Y., Hernandez-Espinosa, N., Pena, R.J. 2013. The influence of drought and heat stress on the expression of end-use quality parameters of common wheat. J. Cereal Sci. 57:73-78.

Longin, C.F.H., Maurer, H.P., Melchinger, A.E., Frisch, M. 2009. Optimum allocation of test resources and relative efficiency of alternative procedures of within-family selection in hybrid breeding. Plant Breeding 128:213-216.

Mao, X., Li, Y., Zhao, S., Zhang, J., Lei, Q., Meng, D., Ma, F., Hu, W., Chen, M., Chang, J., Wang, Y., Yang, G., He, G. 2013. The interactive effects of transgenetically overexpressed 1Ax1 with various HMW-GS combinations on dough quality by introgression of exogenous subunits into an elite Chinese wheat variety. PLoS ONE 8:1-13.

Miles, C.W., van Biljon, A., Otto, W.M., Labuschagne, M.T. 2013. Grain and milling characteristics and their relationship with selected mixogram parameters in hard red bread wheat. J. Cereal Sci. 57:56-60.

Miles, C.W., van Biljon, A., Otto, W.M., Labuschagne, M.T. 2014. The relationship between selected mixogram parameters and rheological and baking characteristics in hard red bread wheat grown in South Africa. J. Cereal Sci. 59:219-223.

Morojele, M.E., Labuschagne, M.T. 2013. Estimates of genetic parameters for quality of wheat cultivars grown in Lesotho. African Crop Sci. J. 21:191-199.

Neacşu, A., Stanciu, G., Sãulescu, N.N. 2009. Most suitable mixing parameters for use in breeding bread wheat for processing quality. Cereal Res. Commun. 37:83-92.

Pon, C.R., Lukow, O.M., Buckley, D.J. 1989. A multichannel, computer-based system for analysing dough rheology. J. of Texture Studies 19:343-360.

SAGL (South African Grain Laboratory) 2013. Analysis procedure and evaluation norms for the classification of wheat breeders' lines for the RSA, as revised by: Sensako, Pannar, ARC-SGI, SA Chamber of Baking, National Chamber of Milling, Grain SA and SAGL.

Walker, A.E., Walker, C.E. 1992. Documentation and user's instructions for Mixsmart. National Manufacturing Division, TMCO. 507 J. Street, Lincoln, NE68508, USA.

\section{Electronic Supplementary Material (ESM)}

Electronic Supplementary Material (ESM) associated with this article can be found at the website of CRC at http://www.akademiai.com/content/120427/

Electronic Supplementary Table S1. Heritability and GCA:SCA ratios for mixograph parameters and selected quality characteristics 